\title{
INFLUENCIA DE LA ARQUITECTURA VERNÁCULA EN LAS BODEGAS DE VINO MEXICANAS
}

\author{
MARÍA JOSÉ FERNÁNDEZ BARBERENA \\ Universidad Iberoamericana de Puebla \\ PAULA REVENGA DOMÍNGUEZ \\ Universidad de Córdoba
}

Fecha de recepción: 25/06/2021

Fecha de aceptación: 02/09/2021

\begin{abstract}
Resumen
La arquitectura vernácula es una importante manifestación de cultura que materializa las formas de entender el entorno y relacionarse con él. La adaptación al paisaje y al medio natural resultan componentes fundamentales de esta arquitectura, pues la topografía, el clima, la vegetación y los materiales disponibles condicionan su emplazamiento, sistema constructivo, espacialidad y forma. México todavía cuenta con una importante muestra de patrimonio arquitectónico vernáculo que forma parte de la cultura de los grupos étnicos y mestizos que conforman el país, y aunque la construcción tradicional haya perdido vigencia, algunos arquitectos contemporáneos están reconsiderando sus ventajas, al tiempo que se está produciendo una revalorización de lo tradicional en el ámbito del turismo.

Estas circunstancias han permeado al sector vitivinícola y favorecido experiencias de construcción de bodegas en las que se trata de recuperar los valores arquitectónicos de una región, con soluciones espaciales y morfológicas adaptadas al medio físico y en las que los materiales autóctonos adquieren protagonismo, aspectos éstos que analizamos en el presente trabajo, incidiendo, además, en el hecho de cómo esas construcciones integradas en el entorno se están convirtiendo en un valor añadido de las haciendas vitivinícolas, que a su función productiva suman una función representativa, atrayendo visitantes por el atractivo que representa la simbiosis entre vino, arquitectura, tradición y paisaje.
\end{abstract}

\section{Palabras clave}

Arquitectura vernácula, Patrimonio vitivinícola, Bodegas, Viñedos, México

Ucoarte. Revista de Teoría e Historia del Arte, 10, 2021, pp.189-211, ISSN: 2255-1905 


\title{
INFLUENCE OF VERNACULAR ARCHITECTURE IN MEXICAN WINERIES
}

\begin{abstract}
Summary
Vernacular architecture is an important cultural manifestation that materializes ways of understanding and relating to the environment. Adaptation to the landscape and the natural environment are fundamental components of this type of architecture, since the topography, climate, vegetation and available materials condition its location, construction system, spatiality and form. Mexico preserves rich examples of the vernacular architectural heritage that forms part of the culture of the country's ethnic and mestizo groups, and although interest in this constructive tradition has largely waned, some contemporary architects are reconsidering its advantages, while the tourism sector is reassessing the value of tradition.

This vision has permeated the wine sector and led to the building of wineries that seek to revive regional architectural values through spatial and morphological solutions adapted to the physical environment in which locally-sourced materials stand out, aspects that we analyze in this paper. Moreover, these constructions, which are integrated in the environment, are becoming an added value for wine estates, thus lending a representative function to their productive function and attracting visitors due to the symbiosis between wine, architecture, tradition and landscape.
\end{abstract}

Key words

Vernacular architecture, Wine heritage, Wineries, Vineyards, Mexico. 
Influencia de la arquitectura vernácula en las bodegas de vino mexicanas

\section{Introducción}

La arquitectura vernácula surgió como respuesta a las necesidades de hábitat de los pueblos nativos. Según la Carta del Patrimonio Vernáculo Construido de 1999, describe al patrimonio vernáculo como la expresión fundamental de la identidad de una comunidad y su relación con el territorio, arraigado a las costumbres y tradiciones, y a la forma en que las comunidades han establecido sus modos de vida. Esencialmente utilizaban recursos materiales existentes y de fácil acceso para la construcción. La arquitectura vernácula está influenciada por las formas de construir (climáticamente confortables) de una región, que ha sido enseñada de generación tras generación. Torres ${ }^{1}$ afirma que siempre se respeta la naturaleza y conservación del entorno, ya que en la vivienda vernácula se llevan tradiciones de carácter sagrado. De esta manera que cuando se sustituyen materiales repuestos para la edificación son devueltos al ecosistema, evitando el impacto que pueda ocasionarse.

Por su parte, Ortiz ${ }^{2}$ argumenta que la construcción de la arquitectura vernácula estará representada por el medio físico que la rodea, por ejemplo, región y clima, siendo factores principales. Por lo que siempre se busca desarrollar una arquitectura que promueva la generación de microclimas para el disfrute y confort en su interior. Torres ${ }^{3}$ menciona que la arquitectura vernácula nació entre los pueblos autóctonos de cada país y ofrece grandes beneficios sustentables mediante el reúso de materiales, de manera que no contaminan. Los proyectos arquitectónicos incluyen un gran respeto por la naturaleza. Así, esta arquitectura no necesita precisamente un arquitecto, puesto que es intuitiva, que responde a las necesidades del individuo y su entorno, manteniendo en equilibrio su economía, sociedad y medio ambiente.

Actualmente la arquitectura ha cambiado mucho, ahora ya no es necesario utilizar materiales regionales, la adaptación al clima y zona, los proyectos arquitectónicos no son adaptados al medio ambiente ni tampoco a la flora y fauna del paisaje, sino a la vanguardia y moda. Sin embargo, se le está dando un realce a la conciencia ecológica y la mitigación del impacto con el ecosistema. Por esta razón, el arquitecto que quiera construir bajo la influencia de la arquitectura vernácula debe emplear materiales reciclables, tomando en consideración el clima, tierra, medio ambiente, entre otros, de tal forma que la obra quede integrada al hábitat. Trillería (2010) dice que a esta arquitectura goza de tres elementos esenciales: (1) nativa, que ha surgido del mismo lugar donde se encuentra, (2) popular, que es concerniente al pueblo, y (3) tradicional, que practica las normas y costumbres del pasado.

La arquitectura vernácula se distingue por la edificación de paredes gruesas elaboradas con varias capas de materiales que logran la protección y aislamiento del clima, de modo que en su interior es fresco y térmico. Esta arquitectura manifiesta la cultura popular del lugar ya que refleja la adaptación al medio y su funcionalidad, es consciente de la importancia de ciertos elementos como el agua, siendo un recurso primordial y en determinadas áreas escaso, por lo que desarrollan métodos como la recolección de agua y reciclaje. Algunos proyectos arquitectónicos de vitivinícolas en México presentan estas características. Por ende, este trabajo tiene con objetivo identificar los elementos característicos de la arquitectura vernácula principalmente de las bodegas de vino del Valle de Guadalupe, Guanajuato, Querétaro, Zacatecas y San Luis Potosí (México), destacando su alto valor patrimonial ya que desde la conquista española se inició la producción de vino en la Nueva España.

Hoy en día se produce el 90 por ciento del vino mexicano en Baja California, a partir de los cincuenta del siglo XX recobró auge el interés por producir vino y, en los últimos años, algunas vitivinícolas se han dado a la tarea de renovar sus instalaciones teniendo presentes los principios de respeto por el entorno y la reutilización de los materiales que están a la mano. Vitivinícolas

\footnotetext{
1 Torres Zárate, 2009: 1-14.

${ }^{2}$ Ortiz, 2015: 104-113.

3 Torres, 2005:20-25
} 
de otras regiones de México han seguido el mismo camino. Para describir estos proyectos se revisan las diversas definiciones que se han dado de arquitectura vernácula con el fin de determinar las características que la conforman. Posteriormente se describen las diferentes manifestaciones vernáculas en la arquitectura mexicana para finalmente referir los proyectos arquitectónicos de los viñedos mexicanos con características vernáculas. Y, por último, se presentan las conclusiones de este artículo.

\section{Definición y elementos que conforman la arquitectura vernácula}

Según el Diccionario de la Real Academia Española la palabra "vernáculo" deriva del latín vernacullus, que significa "doméstico, nativo, de la casa o país propio". Por otra parte, el término "arquitectura vernácula" se define como el proceso de creación arquitectónica por parte del individuo, sin necesidad de un arquitecto, lo cual conlleva un proceso meramente instintivo, resolviendo sus necesidades primordiales que son las de refugio y desarrollo de sus actividades dentro de su entorno ${ }^{4}$. En la arquitectura vernácula, los materiales empleados, al ser regionales, son manejados de manera tradicional. Con ello el uso de los mismos evita caer en el abuso o explotación indiscriminada, lo cual ayuda a que una vez terminada su vida útil se reintegren al medio natural; generando así una arquitectura sustentable ${ }^{5}$.

Para considerarse sustentable un proyecto arquitectónico debe de equilibrar la economía, la sociedad y al medio ambiente. En este caso se crea un ahorro al no recurrir a arquitectos y se construye de manera autónoma, utilizando materiales de la región y dando como resultado una manifestación de la identidad de la comunidad recurriendo a sus tradiciones y a la integración con el paisaje cultural. La característica de sustentabilidad que conllevan las construcciones vernáculas se manifiesta por la utilización de materiales de la región, generando un equilibrio con el medioambiente al tener el menor impacto con el medio físico natural. A lo largo del tiempo fueron concretándose ciertas normalizaciones regionales que dieron lugar a una arquitectura con características propias en donde encontraron expresión los más humildes artesanos y los grandes constructores 6 .

Oliver (2006) define la arquitectura vernácula comprende las viviendas y todos los demás edificios de la gente. Relacionado con sus contextos ambientales y recursos disponibles, habitualmente son construidos por el propietario o la comunidad, utilizando tecnologías tradicionales. Se construyen todas las formas de arquitectura vernácula para cubrir necesidades concretas, adecuando las economías, estilos de vida y los valores de las culturas que las originan. El objeto más común en la arquitectura vernácula urbana es la vivienda, para la cual utilizan materiales de fácil acceso, ya sean desperdicio, artesanales o industriales, o combinación de ellos, la forma de construir se transmite de generación en generación y pueden agregarse elementos con el tiempo.

En la arquitectura vernácula urbana es importante seleccionar los elementos que estén cercanos al área de construcción y que además se adecúen al presupuesto económico. La arquitectura vernácula es una arquitectura heredada de generación en generación, dejando el testimonio de su respeto por la naturaleza y sus ciclos. La arquitectura vernácula expresa la diversidad (clima, materiales y diseños constructivos). Diáñez $z^{7}$ considera que ahora, la arquitectura sostenible busca lo mismo; lograr buenos equilibrios energéticos a base de reconocer las variables de cada lugar para mediante el diseño arquitectónico inteligente (en la vernácula es por vía de la tradición derivada de lentos procesos empíricos de ensayo y error) alcanzar una

\footnotetext{
${ }^{4}$ Landa y Segura, 2017: 67-71

5 Torres Zárate, 2009: 1-14

6 Viñuales, 2007: 15-24.

${ }^{7}$ Diañez Rubio, 2007: 53-55.
} 
eficiencia que en lo vernáculo era por la falta de medios y ahora es por ideología medioambiental o sostenibilidad.

Hoy en día, los desarrolladores y diseñadores de lugares ecoturísticos deben tomar en cuenta los materiales del sitio, utilizar mano de obra local, adaptar las necesidades del proyecto al clima y al entorno. Esto permite abaratar costos y a la vez, los lugareños recuperan la tradición de la construcción vernácula. Lamentablemente la arquitectura moderna ha olvidado nuestros orígenes y ha favorecido la tecnología, la mercadotecnia, y las corrientes de moda. Dejando de lado la relación del hombre con la naturaleza, la montaña, el mar, el viento, el sol, la lluvia, se ha volcado a los materiales y sistemas constructivos industrializados. Sin embargo, la nueva arquitectura ha dado un giro buscando valores, materiales y sistemas propios que a la vez representen el momento que se vive, de tal forma que los modelos de arquitectura moderna toman de la arquitectura vernácula lo autóctono y buscan comunicarse con el medio ambiente natural, lo cual no significa rechazar los avances tecnológicos y las técnicas modernas ${ }^{8}$

A través de las ecotécnias9 (Arias, 1998 citado en Torres, 2011, p. 16) se puede hablar de sustentabilidad en la arquitectura. Los orígenes de ésta se remontan a las edificaciones vernáculas. El desarrollo sustentable es una estrategia que engloba la relación de la gente con su medio ambiente, buscando mejorar la calidad de vida de la comunidad. Este tipo de desarrollo considera las recursos económicos, ambientales y culturales. La arquitectura vernácula tiene un modo de construir emanado de la propia comunidad, es reconocible por su carácter local o regional ligado al territorio, es coherente con su estilo, forma y apariencia, la sabiduría tradicional en el diseño y la construcción es transmitida de manera informal y responde a los requerimientos funcionales, sociales y ambientales aplicando sistemas, oficios y técnicas tradicionales de construcción. ${ }^{10}$

Utiliza materiales renovables; al usar materiales reciclables al término de su vida útil, éstos se integran al ecosistema natural. No altera modos de vida ni patrones tradicionales. Ofrece expectativas a largo plazo coherentes a la protección del medio ambiente. Depende exclusivamente de la economía local o regional con la utilización sólo de sus propios insumos. Individual o colectiva, su ejecución es local. Existe siempre la participación del usuario o la comunidad. ${ }^{11}$ Desde su origen, las comunidades vernáculas presentan propiedades de sustentabilidad. Después de su vida útil, los materiales son reintegrados a la naturaleza de modo que no contaminan. Esta arquitectura se adapta a las diversas condiciones climáticas del planeta, utilizando tecnologías acordes con el ambiente, adaptándose al medio físico.

\section{Particularidades de la arquitectura vernácula mexicana}

México cuenta con una importante muestra de patrimonio arquitectónico vernáculo, que forma parte del conjunto de manifestaciones culturales de los grupos étnicos y mestizos que conforman el país. Debido a la vivienda vernácula podemos conocer las diversas formas de ocupación del territorio, apreciar la formación de los espacios comunitarios y domésticos, reconocer el conocimiento del entorno y su contribución de materiales, así como las técnicas empleadas para construir de la forma más apropiada al lugar. La arquitectura vernácula en México proviene de los conocimientos de las civilizaciones mesoamericanas previo a la colonización y también de los conocimientos arquitectónicos que propagaron los españoles, quienes a la vez traían un bagaje arquitectónico con influencia árabe, sumado al conocimiento y a las costumbres de los esclavos africanos que trajeron consigo, así mismo de la pluralidad de ecosistemas, geografía y tradiciones que se encuentran en el territorio mexicano.

\footnotetext{
8 Torres Zárate, 2011: 16-19, King, J. L, 2001.

9 Torres Zárate, 2011: 16-19.

${ }^{10}$ ICOMOS, 1999.

${ }^{11}$ Ibid.
} 
A raíz de los elementos heredados de la época prehispánica, toma un sentido valioso el espacio arquitectónico. De tal modo que la simplicidad de sus espacios y su organización tienen un profundo sentido de signos y significados. Esta arquitectura se adecúa a las necesidades que cada región presenta, particularmente las climáticas y geográficas, generando al acervo de cientos de años de tradiciones, conocimientos y cultura de los pueblos indígenas de México. La Carta del Patrimonio Vernáculo Construido (1999) ${ }^{12}$ expresa que el patrimonio tradicional o vernáculo construido es la expresión fundamental de la identidad de una comunidad, de sus relaciones con el territorio y al mismo tiempo, la expresión de la diversidad cultural del mundo.

Hay factores comunes en las construcciones vernáculas en México como el uso de materiales renovables, utilización de materiales reciclables los cuales al término de su vida útil pueden reintegrarse al ecosistema natural sin alterar el medio ambiente, los individuos de la comunidad son los que diseñan y construyen sus casas considerando el clima y hábitat natural de su zona para adaptarse a ella y a sus necesidades. Actualmente, hay una tendencia arquitectónica de retomar lo vernáculo buscando la reducción de costos de las obras, adaptación al medio, considerar el clima del lugar, la trayectoria solar, los materiales y técnicas locales. De tal modo que se busca una arquitectura menos consumidora de la naturaleza, cuyas propuestas implican menor gasto de energía, utilizar materiales que se adecúen a las condiciones climáticas del lugar, buscar el empleo eficiente de los recursos disponibles sin dejar a un lado los avances científicotecnológicos.

Resulta significativo, en este sentido, el caso de Barragán como continuidad o adaptación de lo vernáculo; su obra retoma los valores de la arquitectura vernácula mexicana para enriquecer la arquitectura contemporánea y reconsidera las bases que originaron la primera, entre ellas, la adaptación al sitio y el uso de materiales locales, con el fin de recrear una arquitectura contemporánea que no ha perdido su identidad y que bajo la estética de las expresiones mínimas logra una coherencia con su tiempo. ${ }^{13}$

\section{Arquitectura vernácula contemporánea en los viñedos del Valle de Guadalupe y otras regiones en México}

La producción de vino es una actividad económica con un importante legado cultural. Un complejo vinícola comprende espacios para el prensado de las uvas, la maceración, la fermentación, el filtrado y el embotellado de los caldos; así como la bodega donde se almacena y añeja el vino, generalmente en barricas de madera. Las cavas deben tener una temperatura menor a la del exterior y una humedad controlada por lo que generalmente están bajo tierra. En los últimos años el auge de este sector ha aumentado y su crecimiento ha requerido buscar nuevos recursos para saciar el interés de sus visitantes y clientes. Las bodegas dejan de ser lugares de producción para ser objeto de cultura y turismo. Desarrollan proyectos donde integran la elaboración, conservación y crianza de sus vinos, con la venta, las visitas y las catas. Hay algunos casos donde incluyen restaurantes y hoteles boutique. Todo esto buscando una asociación con el paisaje de tal modo que se relacionen la elaboración del vino, el entorno natural y las capacidades humanas. Buscan comunicar valores y están desarrollando una nueva cultura que atrae turistas, logrando impulsar una nueva demanda social y desarrollar un nuevo espacio de consumo de servicios alrededor de lo que se conoce como turismo cultural. ${ }^{14}$

La industria se ha visto impulsada gracias a la variedad de actividades que se han desarrollado en torno a la vitivinicultura: visitas a los viñedos, recorridos explicativos y las salas de degustación donde se pueden apreciar los vinos que producen, salas de ventas donde no solo venden vino, sino algunas también venden productos propios de la región como aceite de oliva, vinagre,

\footnotetext{
12 ICOMOS, 1999.

${ }^{13}$ Chaos Yeras, 2015: 62-73.

14 Revenga, 2002: 113-124.
} 
quesos, entre otros. García y Rivera ${ }^{15}$ consideran que es parte de la hipótesis de que la arquitectura funciona como un vehículo legitimador y que cada una expone un significado diferente de "lo vernáculo", a través de una diversidad de tipologías producidas que persiguen el mismo fin: atraer turismo.

Existe un gran interés entre los amantes y consumidores del vino por saber más sobre todo lo que se relaciona con él: sus viñedos, visitar las bodegas, saber sobre las técnicas de elaboración, conocer los terruños, etcétera. Es un producto alrededor del cual se han desarrollado diversas actividades y experiencias relacionadas, por lo que recorrer los paisajes del vino, conocer su arquitectura, comprender cómo ha evolucionado con el tiempo, enriquece la percepción de cualquier visitante ya que permite adentrar en su dimensión cultural y las diversas regiones donde se produce el vino. Uno de los principales destinos enoturísticos del país es el Valle de Guadalupe, donde se han desarrollado en los últimos años varios proyectos tanto vitivinícolas como hoteleros y gastronómicos. ${ }^{16}$

Actualmente muchas empresas incluyen en su cultura corporativa valores donde se respete la ecología y el entorno del viñedo. La sensibilidad contemporánea está considerando prioritario el cuidado del medio ambiente y el amor por la naturaleza. En opinión de García y Rivera en varias casas vitivinícolas se puede identificar un vínculo entre la elaboración del vino y la reincorporación de materiales de desecho. Se identifica así en su arquitectura cierto "sello" que se sustenta de lo vernáculo (hecho en la región y autoconstruido) y a su vez se extiende por su entorno inmediato, traspasa el paisaje urbano, descubriéndolo. Y en dicho sello radica ese valor añadido que lo está impulsando como marca-destino en el sector vinícola, pues su arquitectura emana del propio proceso que apoya la industria, la proyecta y la sustenta. ${ }^{17}$

Una característica diferenciadora de la zona vitivinícola de Baja California ha sido que han logrado enlazar la arquitectura con el paisaje vinícola. Existe la cultura del reciclaje y saben aprovechar todos los desperdicios que se encuentran en el lugar. Esta nueva arquitectura está legitimando su manera de hacer al reciclar y construir con lo que encuentra en su entorno. Los siguientes proyectos vitivinícolas contemporáneos presentan características de la arquitectura vernácula, la mayoría se encuentra en Baja California y han sido proyectos del Arquitecto

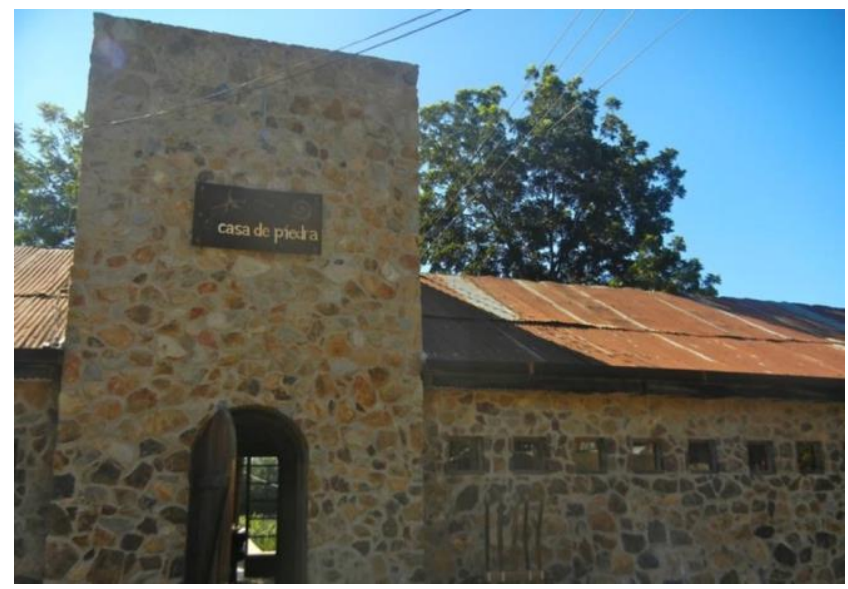

Fig.1. Construcción con piedras seleccionadas de la región en Vinicola Casa de Piedra. Fuente: Fotografía de Javier Zayeck, TAC.

\footnotetext{
15 García/Rivera, 2019: 267-284.

16 García/Meraz/Díaz, 2018: 690-711.

17 García/Rivera, 2019: 267-284.
} 
Alejandro D'Acosta y algunas en otras regiones de México. Se presentan en orden cronológico por año de construcción (Figura 1).

Vinícola Casa de Piedra, creada en 1995, esta se encuentra en San Antonio de las Minas en Baja California. Este proyecto fue elaborado por el Taller de Arquitectura Contextual (TAC), siendo un despacho de arquitectos cuyo director es el arquitecto Alejandro D'Acosta. Su filosofía es buscar el equilibrio de los ecosistemas, sin abandonar la estética, el confort y la fortaleza de la arquitectura. Busca que sus proyectos sean sustentables y sostenibles y que la arquitectura vernácula se convierta en contemporánea ${ }^{18}$. El proyecto de Casa de Piedra es un proyecto simbólico, discreto, de escala humana. La piedra es parte modular del concepto, se recogió piedra por piedra. Este material forma parte del entorno y es en sí el elemento emblemático que concentra el tiempo y la evolución de toda Baja California. Casa de Piedra pareciera un edificio antiguo del siglo XVI, por el tiempo contenido dentro. También se utilizó madera de barricas de vino y láminas usadas.

El arquitecto Alejandro D'Acosta describe que al llegar al sitio y cuando penetras sus muros sientes el devenir el tiempo, de los materiales reciclados, estos te hablan de su historia, huelen a vino, porque cada elemento de madera ya fue "tonel de vino", cada material estuvo ahí, antes de que se concibiera como parte de la construcción

Vinícola Santo Tomás, creada en 1998, desarrollada también por TAC. Esta bodega se encuentra en el Valle de Santo Tomás en Ensenada, Baja California. De acuerdo con Alejandro D'Acosta se buscó una ubicación adecuada que fuera eficaz considerando los accesos, los vientos, los cultivos, el equipamiento, pero optaron también porque estuviera en una pequeña montaña que sirviera como hito en el paisaje. De tal suerte que la disposición fuera eficaz en las funciones de energía y de fabricación de vino. Se desarrolló un sistema radial reconocido como el más eficiente para la producción industrial y que contiene menos distancias entre sus partes y por ende el más eficaz y cuidado para la producción del vino, de manera que se eliminaron el uso de bombas y todos los procesos son por gravedad. Para regular la temperatura, se cubrió el edificio para aislarlo con tierra del lugar y se construyeron muros de $90 \mathrm{~cm}$. de espesor. Las cavas están bajo el nivel del subsuelo, optimizando así el recurso de pérdida de calor y dominio de la temperatura deseada ${ }^{19}$ (Figura 2).

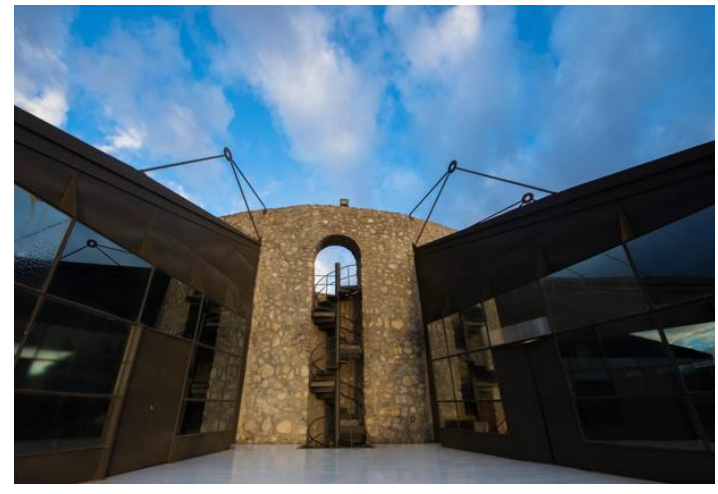

Fig.2. Sistema radial con acero y piedras en Bodegas de Santo Tomás Fuente: Fotografía de Javier Zayeck, TAC.

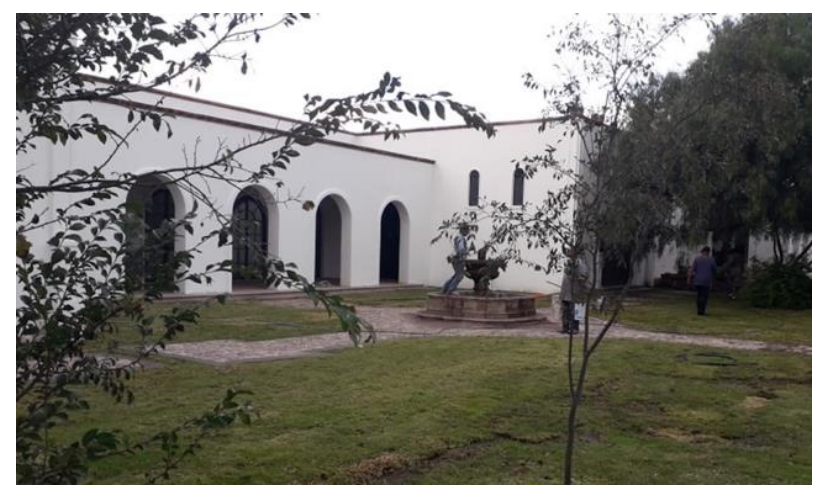

Fig.3. Construcción tipo hacienda con caballerizas adaptadas en Vinícola Dos Búhos. Fuente: Fotografía de Vinícola Dos Búhos.

\footnotetext{
18 ArchDaily, 2014.
}

${ }_{19}^{19}$ D'Acosta (s. f.). 
Se utilizaron 10.000 neumáticos de auto para hacer las contenciones del terreno y controlar la temperatura con un aislante natural al enterrar la planta. Existe un conducto de aire entre el terreno y las llantas. Las que se mueven son las máquinas en lugar del vino gracias al esquema circular, explica el arquitecto Alejandro D'Acosta. Se diseñó un sistema de gravedad para que el vino circule dentro del edificio de arriba hacia abajo sin necesidad de bombas que oxigenen de más el proceso de fermentación del vino. Los procesos son lineales para que cada parte se adecúe, en su momento, a su propio uso. Los materiales utilizados son principalmente: tierra y basura de la región como madera, postes de luz, acero en vigas, diferentes perfiles, pero principalmente tierra del lugar utilizando el sistema de "tapial" utilizado en Baja California desde hace mucho tiempo. Prácticamente casi todos los materiales son reciclados o del lugar, como la piedra que sostiene la planta ${ }^{20}$. Dos Búhos, creada en 2003. Se encuentra en San Miguel de Allende, Guanajuato. Eran bodegas y se reutilizó todo lo que se encontró en el lugar. Experimentaron con adobe, pacas aplanadas con cemento, entre otros elementos la construcción es como una hacienda hecha con tabiques con molduras de cemento y vigas de madera, con doble altura para controlar la temperatura. Buscaron la orientación correcta para aprovechar las diferentes épocas del año: crearon patios y arcadas, jugaron con las sombras y el microclima. Es una arquitectura minimalista y regional. Adaptaron las caballerizas para hacerlas bodegas de producción. Los muros son aislados. Elaboran vinos orgánicos con levaduras naturales (Figura 3) (Dos Búhos, comunicación personal, 24 de octubre de 2019).

Solybarro, fue creada en 2005. Es una vinícola suizo-mexicana en el Valle de Guadalupe, el terreno donde se edificó tenía rocas, matorrales, arcilla, granito, todo lo requerido para crear y construir la nueva bodega. Construida ecológica y orgánicamente, por su propio dueño Aimé Desponds, con tierra arcillosa o barro, mezclado con paja, agua y piedra. Sus muros son anchos para conservar una temperatura estable, factor indispensable para el proceso de envejecimiento del vino en barricas. Esta bodega es un complejo de construcción natural que combina el diseño ecológico, orgánico y sustentable, y a la vez, destaca texturas, formas y color en un sólido edificio. Los edificios son una de las características principales de Sol y Barro, construido en el estilo de "cob" usando la tierra misma y creado por Aimé Desponds, que es diseñador, artista, viajero y enólogo. El efecto es una hermosa construcción escueta que es una parte natural del paisaje. El dueño de Sol y Barro ha ido construyendo poco a poco los edificios que conforman su viñedo y busca principalmente alinear su vinícola con la naturaleza y con la producción sustentable (A. Desponds, comunicación personal, 20 de noviembre de 2019).

La construcción de "cobs" utiliza manos y pies para formar masas de tierra mezcladas con arena y paja, una experiencia sensorial y estética parecida a la escultura con arcilla. La palabra "cob" proviene de una antigua raíz inglesa que significa un bulto o una masa redondeada. El "cob" se presta a formas orgánicas: paredes curvas, arcos y nichos. Este tipo de construcciones son frescas en verano y cálidas en invierno. Su resistencia a la lluvia y al frío lo hace ideal para climas fríos y para condiciones desérticas $^{21}$ (Figura 4).

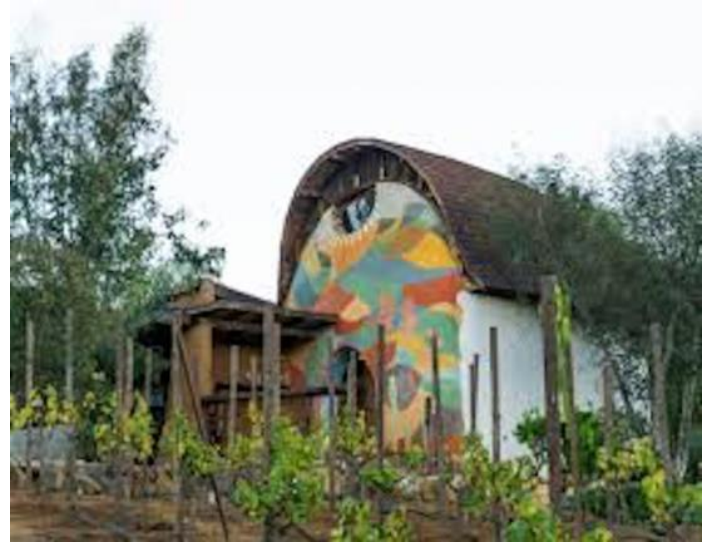

Fig.4. Construcción estilo cob en Solybarro Fuente: Fotografía de Aimé Desponds.

${ }^{20}$ Ibid.
21 "Cob Building: What is Cob?" En https://www.thehollies.ie/cob/ [25 octubre 2019]. 
Vinícola Paralelo, fundada en 2006. Se encuentra en el Valle de Guadalupe. En este proyecto, también del despacho de arquitectura TAC, el respeto a la ecología es explícito. El proyecto se diseñó desde el paisaje, como parte integral, de manera que al llegar al lugar se mimetiza, casi no se aprecia. En este tipo de arquitectura verde, el entorno pone los elementos precisos, los arquitectos solo recompusieron la tierra del lugar. El edificio habla de tiempo y naturaleza, el proceso de construcción se basa en la arquitectura vernácula, los muros de "tapial" han existido desde hace mucho tiempo, algunas de las misiones de Baja California están construidas con ese material y aún permanecen. El utilizar el suelo como material de construcción les otorga la utilización eficiente de los recursos, a la vez que remite y reconforma a nuestros orígenes más antiguos.

Surge un diálogo muy interesante entre el espíritu del lugar y el espíritu de la época al enlazar las tendencias arquitectónicas contemporáneas con los materiales propios del lugar. El arquitecto Alejandro D'Acosta cuenta que en Baja California son escasos los materiales producidos regionalmente por lo tanto aprovechan los desechos de los Estados Unidos que bajan por toda la península. Esa cultura del reciclaje y aprovechamiento de los desperdicios está presente en toda la región, por lo que trae como consecuencia una nueva arquitectura vernácula; estos materiales que ya se encuentran en el lugar se convierten en elementos para usar. Algunos de estos elementos reutilizados son parte del proyecto Paralelo.

Estación de Oficios del Porvenir, creado en 2007. Este es un centro dedicado a la enseñanza de temas como la viticultura, vinificación, microbiología y añejamiento. Las instalaciones y servicios son aptas para que los alumnos elaboren su propio vino por medio de la molienda, fermentación, prensado, añejamiento en barrica y embotellado. Este es otro proyecto de TAC. Los edificios están hechos con desechos, lo que habla de una responsabilidad tácita respecto a lo que se produce. En el proceso productivo están implicados directamente los materiales de reciclaje. En los años noventa, la creciente y nueva enología mexicana demandaba nuevas respuestas e instalaciones, así como nuevos conceptos que prestaran atención a las incrementadas necesidades de aprendizaje, de esta forma nació la idea de una "vinícola pública" donde los interesados pudieran estar en contacto con la producción y elaborar vino con asesoría, guía y pasión, señala el arquitecto Alejandro D’Acosta.

El edificio está diseñado pensando en la auto sustentabilidad, por lo que está hecho con desechos, evidenciando una responsabilidad respecto a lo que se produce. Baja California recibe una gran variedad y materiales de California, lo cual entraña una pródiga fuente de materia prima para desarrollar componentes constructivos. Al ser organizados constructivamente en un lugar muestran su lado estético y funcional ${ }^{22}$. (Figura 5).

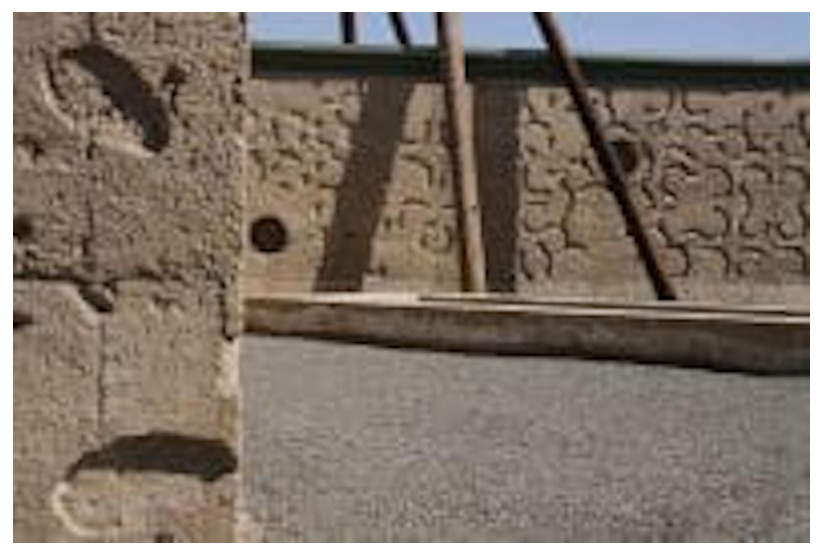

Fig.5. Tapial reusado en Paralelo. Fuente: Fotografía de Javier Zayeck, TAC.

\footnotetext{
${ }^{22}$ D’Acosta (s. f.).
} 
Cuna de Tierra, creada en 2011. Se encuentra en San Luis de La Paz, Guanajuato. Este proyecto fue elaborado por el Centro de Colaboración Arquitectónica (CCA) conformado por los arquitectos Ignacio Urquiza Seoane y Bernardo Quinzaños Oira. El arquitecto Ignacio Urquiza comenta sobre el proyecto, que la solicitud inicial del cliente fue reemplazar una antigua plataforma de observación en medio de las vides. Se le propuso extender el programa de la torre original diseñando una pequeña plaza, unos $60 \mathrm{~cm}$ por debajo del nivel de suelo de las vides, la estructura de la torre y en el interior de ella, un pequeño espacio de degustación de vino. A partir de ello se propuso continuar una extensión del programa para construir la vinícola. El proyecto consistió en seis pabellones o módulos, en un solo nivel y conectados mediante plazas y andadores. Su propuesta parte de la fragmentación de los espacios para acomodar el programa y relacionar de diferente manera las etapas de producción del vino, utilizando esta separación de los volúmenes, las sombras y vacíos para hacer más eficiente el comportamiento térmico de los edificios. $^{23}$

Para integrar el proyecto al paisaje y al viñedo, se examina la relación entre la producción del vino, el sitio, el usuario y el principal material en uso: el tepetate colado, el cual efectivamente completa las necesidades requeridas en el programa. Los dos ejes rectores del proyecto fueron la particularidad del entorno natural del viñedo y los requerimientos técnicos del programa arquitectónico. Por una parte, la aproximación al lugar a través de la tierra, la misma que alimenta las vides y colorea el paisaje, que es empleada en el sistema constructivo de tepetate colado. Por otra, la fragmentación del programa en volúmenes que corresponden a los pasos del proceso de elaboración del vino y su distribución, atendiendo al orden de las operaciones en este ciclo. ${ }^{24}$

Dentro de la arquitectura vernácula se retomó este elemento: la tierra del viñedo es el componente constructivo básico del proyecto, el cual crece a partir de un sistema estructural de muros de tepetate, material resultante de las excavaciones. El proyecto se convierte en sí mismo en la exigencia del uso de materiales locales y acabados naturales para lograr la mejor unión con su contexto a través de su aspecto, expresión constructiva y fundamentos de sustentabilidad. Los principales elementos constructivos son los muros de tepetate colado de 30 centímetros de espesor y los pisos de concreto pulido para facilitar el mantenimiento y limpieza que se requieren en procesos de producción. La composición de la tierra con la madera y el concreto -todos obtenidos en zonas cercanas al sitio-, busca transmitir a los trabajadores y visitantes que el resultado arquitectónico se obtiene a partir de la riqueza de su contexto natural. ${ }^{25}$

En esta composición son importantes tanto los llenos como los vacíos de los patios interiores y de las plazas entre volúmenes que, aparte de operar como espacios de trabajo, permiten la iluminación y ventilación natural de los espacios interiores. ${ }^{26}$ Un requisito determinante para conservar correctamente el vino en la necesidad de oscuridad, por lo

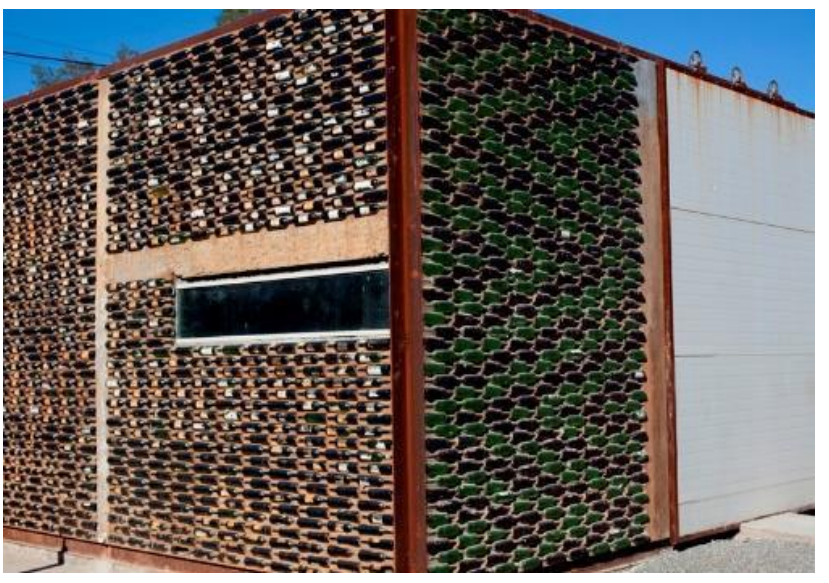

Fig.6. Madera y botellas de vidrio recicladas en la Estación de Oficios. Fuente: Fotografía de Javier Zayeck, TAC.

\footnotetext{
${ }^{23}$ Urquiza, Ignacio (s. f.).

${ }^{24}$ Ibid.

25 ArchDaily, 2013.

26 Urquiza, Ignacio (s. f.)
} 
que la relación de lleno y vacío se convierte en la razón de ser propia de este proyecto. Todas las entradas de luz del conjunto miran hacia el norte, generando una iluminación natural indirecta al interior. La proporción de cada volumen, con sus muros de tepetate colado orientados de oriente a poniente, generan sombras durante el día que cubren a los volúmenes vecinos, estabilizando la temperatura al interior. ${ }^{27}$ (Figura 6).

Por lo tanto, usando el nombre de la vinícola como inspiración conceptual (Cuna de Tierra) y la conexión con su entorno, este proyecto muestra la relación entre la producción del vino y el sitio donde se encuentra este viñedo. La tierra, como el principal elemento para el crecimiento de la vid, se transforma en el principal material para la edificación de un conjunto de volúmenes que por su materialidad se introducen dentro del paisaje existente. La bodega se integra en los viñedos en una construcción de tepetate, acero y $\operatorname{madera}^{28}$ (I. Urquiza, comunicación personal, 7 de noviembre de 2019).

Encuentro Guadalupe, fue creado en 2011. Graciastudio fue el despacho de arquitectos que llevó a cabo el proyecto en el Valle de Guadalupe. Hotel que se encuentra sobre una colina rodeada de viñedos. Una de las proposiciones principales fue no intervenir directamente al terreno, pues parte de la filosofía del proyecto es respetar la naturaleza en la mayor forma posible. Se diseñó una estructura limpia de acero, la cual eleva del suelo al esqueleto de la habitación para no tener contacto con el medio. Con la utilización de acero para forrarla, el cual a lo largo del tiempo va exhibiendo distintas tonalidades, se logra una armonía entre el medio y la obra. ${ }^{29}$

Es una arquitectura consciente y ecológica para el diseño de un hotel que se mimetiza con el majestuoso paisaje rodeado de viñedos. Se usó principalmente acero y madera ecológica de tala controlada y materiales reciclados. La sencillez de las líneas y el uso de materiales autóctonos, fueron el diseño elegido para resaltar el ascetismo del desierto y acentuar cualidades indígenas de la zona. Se diferencia por mantener un respeto por la naturaleza sobre la que se encuentra. En Encuentro Guadalupe se presenta la ocasión de apreciar los paisajes y la naturaleza a través

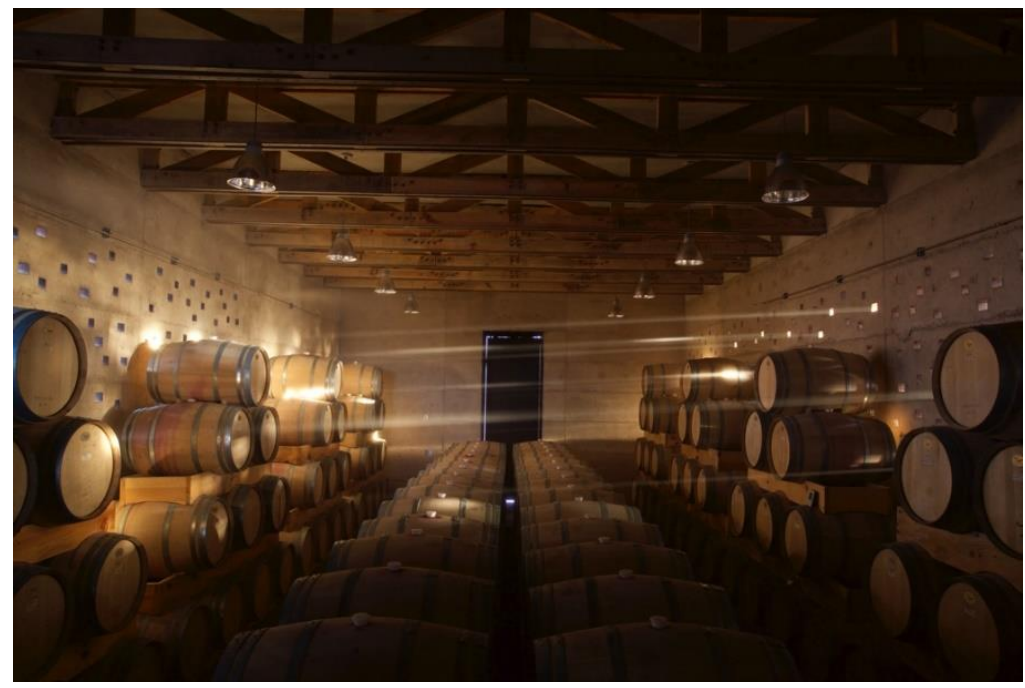

Fig.7. Solsticio de invierno en Cuna de Tierra. Fuente: Fotografía de Ignacio Urquiza, CCA.

\footnotetext{
27 Ibid.

28 Ibid.

${ }^{29}$ Archdaily, 2012. Teorizando1arquitectura, 2018.
} 
de una arquitectura sobria, donde se distingue una armonía entre el medio ambiente y la obra. ${ }^{30}$ (Figura 7).

Vinícola Vena Cava, creada en 2012. Este es un proyecto más de TAC. Esta bodega se encuentra en la región vitivinícola del Valle de Guadalupe. Esta es la primera vinícola de autor que se construye en México, subraya el arquitecto Alejandro D'Acosta. Buscando simbolizar la filosofía de la casa en las edificaciones, en la que el enólogo fue marino y los viñedos se convirtieron en su nueva forma de vida, el edificio forma parte de un complejo hotelerogastronómico, dentro del cual cada ingrediente está cuidado y efectuado in situ, el vino es uno de ellos. Este proyecto es una práctica de reciclaje, pero es más un programa que colabora con el paisaje, empleando deshechos marinos, nos planteó una forma de unir el mar con el valle, armonizando con el paisaje los desechos y la basura ${ }^{31}$.

Se caracteriza por tener una ubicación que trabaja con el paisaje y la funcionalidad. Se ordenó buscando la eficiencia energética y de la fabricación del vino. Para controlar la temperatura, aislaron el edificio cubriéndolo con la tierra del lugar, para lo cual utilizaron los cortes en bruto, dejando el terreno expuesto y trabajando solo los pisos y los techos, los cuales están hechos con barcos desechados por el puerto para ser usados como bóvedas de canon, al estilo de los antiguos constructores quienes construían barcos como iglesias ${ }^{32}$ (Figura 8).

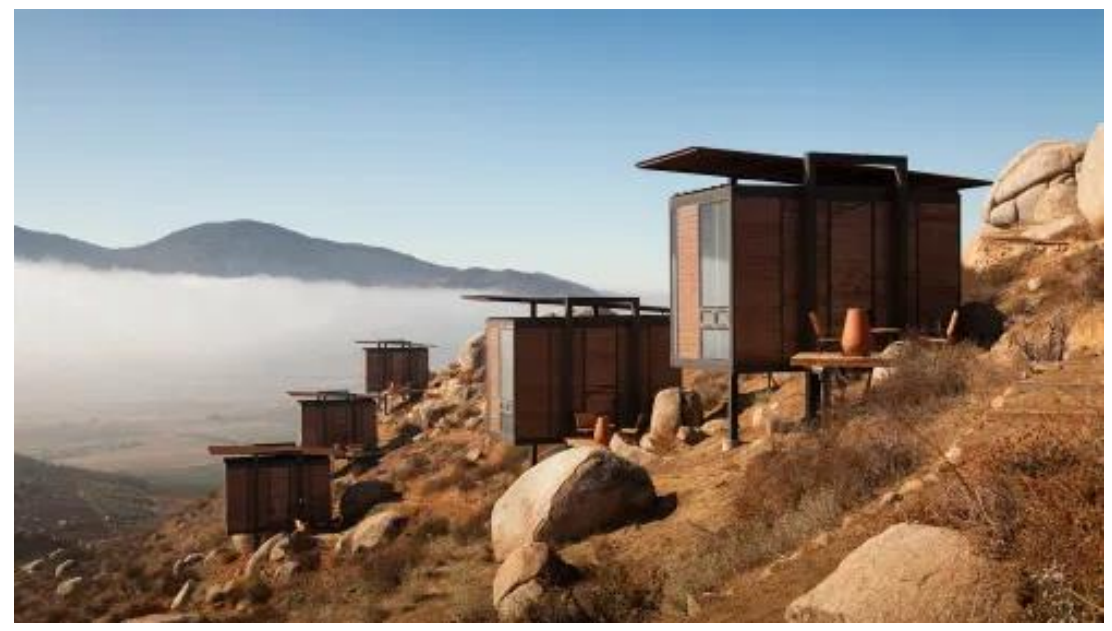

Fig.8. Estructura de acero y madera para elevar la habitación en Encuentro Guadalupe. Fuente: Fotografía de Luis García, Edgar Lima, Arquine.

Clos de Tres Cantos, creado en 2014. En este proyecto, realizado también por TAC, se buscó integrar el contexto físico, como el cultural, asumiendo el sitio y su topografía. En este proyecto, el respeto a la ecología es determinante. Benítez, M. J. dice que su visión está alineada con el criterio biofílico donde la función de los edificios está en armonía con la naturaleza como una necesidad de afiliarse a la vida. La bodega es un monasterio moderno diseñado para contemplar sin interés y conectar a la gente con la naturaleza. En este proyecto, se utilizaron materiales reciclados, de segunda mano y locales lo cual va de la mano con su mensaje de sustentabilidad.

\footnotetext{
${ }^{30}$ Arquitecturayempresa, 2014.

${ }^{31}$ D'Acosta, Alejandro. (s.f.).

32 Ibid.
} 
Las características principales de esta bodega son: (1) el viñedo está conectado a la ecología particular del lugar, respetando la flora y la fauna. Sus vinos son orgánicos por lo que nutren sus viñedos con extracto de algas marinas y composta, elaborada con residuos del lugar; (2) el viñedo rodea el monasterio moderno y como "clos" (muro) lo protege, aislándolo del exterior; (3) las variedades de viñas plantadas coinciden con el suelo, granito y arena del lugar, que se adaptan a las altas temperaturas del verano y la insuficiencia de lluvia. Siembran varietales que se adecuan al calentamiento global debido al cambio climático; (4) se desarrolló un humedal para concentrar agua de lluvia, entregándola a la capa freática (acumulación de agua subterránea) y manteniendo la biodiversidad y la flora y fauna locales; y (5) es una bodega sostenible construida con materiales naturales, locales y de segunda mano o reciclados para no afectar la huella de carbono. Los materiales utilizados son piedra laja procedente de una mina local, cortada a mano. Los demás materiales son materiales de segunda mano o reusados como botellas, maderas, vidrio y hierro de los barcos de Ensenada. Los techos del edificio están diseñados para soportar paneles solares con el fin de operar toda la bodega con energía solar (M. J. Benítez, comunicación personal, 24 de octubre de 2019) (Figura 9)

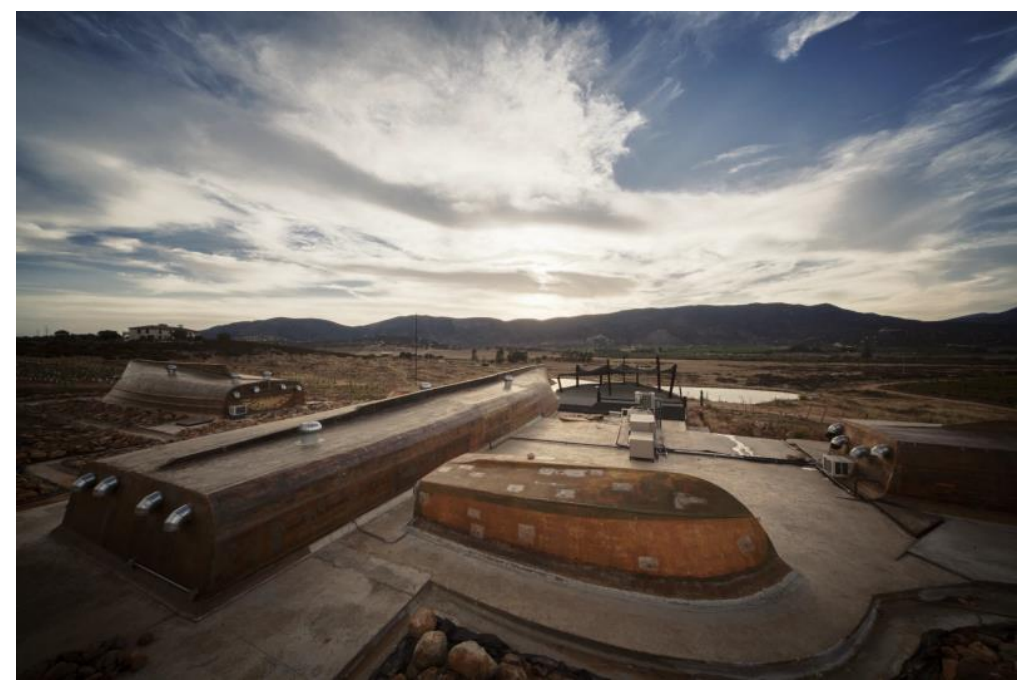

Fig. 9. Casco de barcos y elementos marinos como bóveda de cañón en Vinícola Vena Cava Fuente: Fotografía de Javier Zayeck, TAC.

Monte Xanic, empresa creada en 2014. El arquitecto Juan Garduño estuvo al frente del ambicioso proyecto de una de las principales vitivinícolas del Valle de Guadalupe. Los directivos de Monte Xanic tenían como intención crear un espacio que además de ser funcional marcara la pauta de las vinícolas en México, por ello, después de realizar un concurso entre varias firmas de diseño, se decidieron por el proyecto del arquitecto Juan Garduño, el cual tomaba en cuenta la piedra del lugar para comunicar la idea de que el espacio continúa la ladera de la montaña. ${ }^{33}$ Desarrolló un proyecto sustentable y bioclimático, logrado con la integración de estrategias de conservación de recursos energéticos y la incorporación de materiales locales. Estas son las características principales del proyecto: El programa requería reutilizar una nave industrial posicionada en el talud de la montaña y duplicar el tamaño proveyendo una planta de producción con los elementos necesarios para modernizarse.

\footnotetext{
33 Teorizando la arquitectura, 2018.
} 
Juan Garduño sustenta que la propuesta fue cortar la pendiente natural para colocar los nuevos espacios (sala de barricas, embotellado y almacenaje) dentro de la montaña, para que el edificio se fusionara con el entorno y la ampliación no participara visualmente. La producción enológica requiere de gravedad, por lo que la colocación de los espacios en sus diferentes niveles responde a las necesidades de la operación, la uva cosechada entra en el nivel superior (sala de tanques de fermentación) y el producto terminado sale por el nivel inferior. El oficio de producir vino es un trabajo que conforma necesariamente un proceso limpio y eficiente, el complemento de hospitalidad que se tiene que adjuntar para generar una interacción con el mercado requiere un recorrido que participe del proceso pero que no intervenga en la producción, lo cual se resolvió a base de recorridos paralelos en el cual el invitado puede observar el proceso en un recorrido independiente, siendo una manera innovadora de conocer la vinícola. ${ }^{34}$

El resultado de mantener la bodega existente con la propuesta de integrarla al entorno, la adecuación climática y generar una nueva imagen, generó como respuesta envolverla con una segunda piel que satisficiera las tres premisas de una manera económica, eficiente y creativa, por lo que se tejió con cuerda de henequén, lo cual añadió dinamismo con el movimiento e integración al entorno. Para recuperar la montaña, el nuevo edificio inferior se recubrió en sus muros exteriores con adobe fabricado con la tierra del sitio y arena con vegetación endémica en sus cubiertas. Los dos volúmenes se conectan por medio de una losa de concreto color cabernet sauvignon en la cual la luz del sol ingresa por las perforaciones obteniendo iluminación natural que en su reflejo interpreta racimos de uvas en el piso y los muebles de la terraza. ${ }^{35}$

En este nivel es donde se realizan los diferentes tipos de degustaciones y catas, agregaron un viñedo muestra con las cepas producidas en la zona para que el visitante esté en contacto directo con la materia prima del vino. ${ }^{36}$ Gracias a la integración de estrategias de conservación de recursos energéticos (generadores alternativos de energía, sistemas de reutilización del agua, manejo inteligente de residuos, entre otros) y a la incorporación de materiales locales, se logró una relación simbiótica con el entorno e impulsaron la salvaguarda del patrimonio natural de la región (J. Garduño, comunicación personal, 30 de octubre de 2019) (Figura 10).

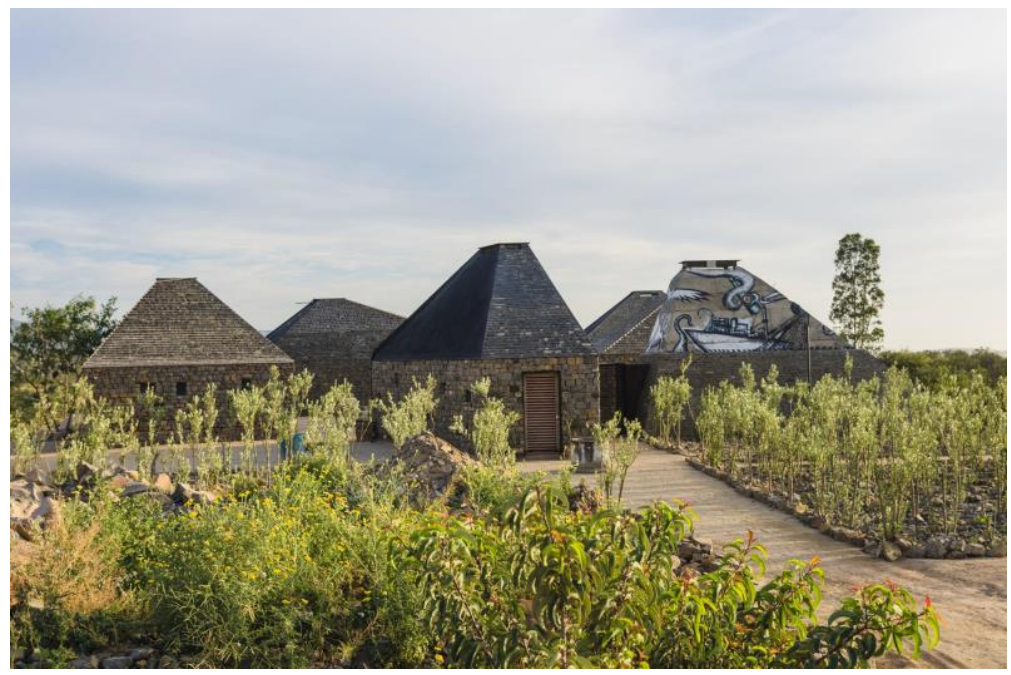

Fig. 10. Monasterio moderno de Clos de Tres Cantos. Fuente: Fotografía de Javier Zayeck, TAC.

\footnotetext{
34 Arquitectura Panamericana, 2016.

35 Ibid.

36 Ibid.
} 
Viñedos de Coté, creada en 2014. Este viñedo se encuentra en Ezequiel Montes, Querétaro. Con los años la bodega se ha ido transmutando y ha dado espacio a actividades paralelas a la operación del viñedo, tales como las visitas al viñedo, ya que cuenta con un magnífico terreno de 3.5 hectáreas. Para resolver este reto recurrieron a Serrano Monjaraz Arquitectos. Este proyecto debía contemplar la operación y además garantizar que los visitantes pudieran pasear por los viñedos, las salas de tanques, la embotelladora y la bodega en el sótano. Los espacios exclusivos para los visitantes son: el bistró para la degustación y compra de vinos y diversos alimentos, así como un salón de usos múltiples con restaurante para eventos, todo esto en un total de cinco mil m2. ${ }^{37}$ Un factor muy importante a tomar en cuenta, señala Serrano Monjaraz, era el procedimiento de hacer vino en el que la gravedad juega un papel preponderante por lo que habría que buscar que las formas y niveles del terreno favorecieran este proceso.

La uva, por una gran rampa, se sube a la azotea, para ser despalillada y prensada, para subsecuentemente bajar a los tanques de acero por gravedad y finalmente se deposita en barricas para su añejamiento, el tiempo que sea necesario. Una vez concluido este proceso se inicia el embotellamiento y la comercialización. Para prescindir del uso de equipos de refrigeración y controlar la humedad, se construyó un sótano de seis metros de profundidad, aprovechando la geotermia de la excavación y ahorrando al máximo el uso de energía. Se manufacturaron miles de bloques con la tierra obtenida de la excavación del sótano y con ellos se construyó la retícula de columnas de cuatro metros por cuatro metros ordenada de acuerdo con el trazo de las líneas de las vides. También se hizo una cubierta a la bodega utilizando perforaciones logradas con la inserción de copas de cristal, elemento indispensable para el disfrute del vino, que se abren en los cuatro puntos cardinales y marcan los principales accesos hacia la entrada general, hacia el viñedo, hacia el jardín con lago y hacia la rampa junto al huerto de higueras y olivos. Este volumen rectangular se remata con una bóveda de madera y metal que remite al tradicional sello de las botellas de vino. ${ }^{38}$ (Serrano Monjaraz, comunicación personal, 11 de noviembre de 2019) (Figura 11).

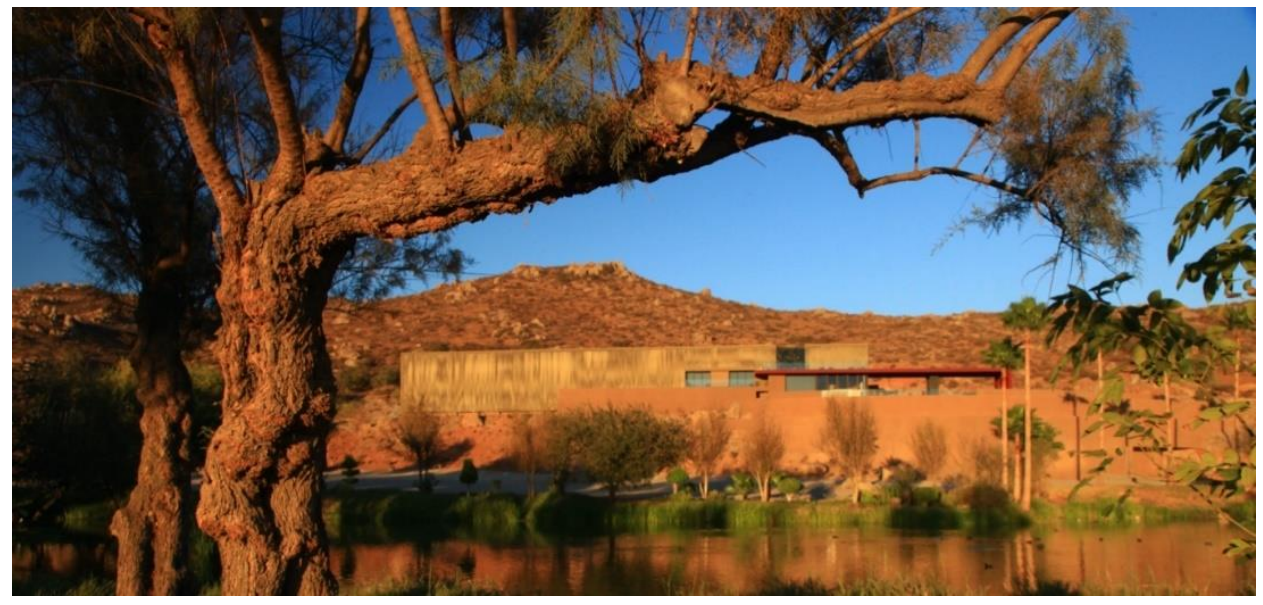

Fig. 11. Integración con el entorno en Monte Xanic Fuente: Fotografía de Sófocles Hernández, Garduño Arquitectos.

Vinícola Bruma y hotel boutique Casa 8, creada en 2015. Es un proyecto conformado por una vinícola, hotel y villas. El despacho TAC del Arquitecto Alejandro D'Acosta fue el que elaboró este creativo proyecto en el Valle de Guadalupe. Tanto la vinícola como el hotel

\footnotetext{
${ }^{37}$ Arquitectura Panamericana, 2014.World-architects.com, 2014.
}

38 Arquitectura Panamericana, 2014.World-architects.com, 2014. 
Influencia de la arquitectura vernácula en las bodegas de vino mexicanas

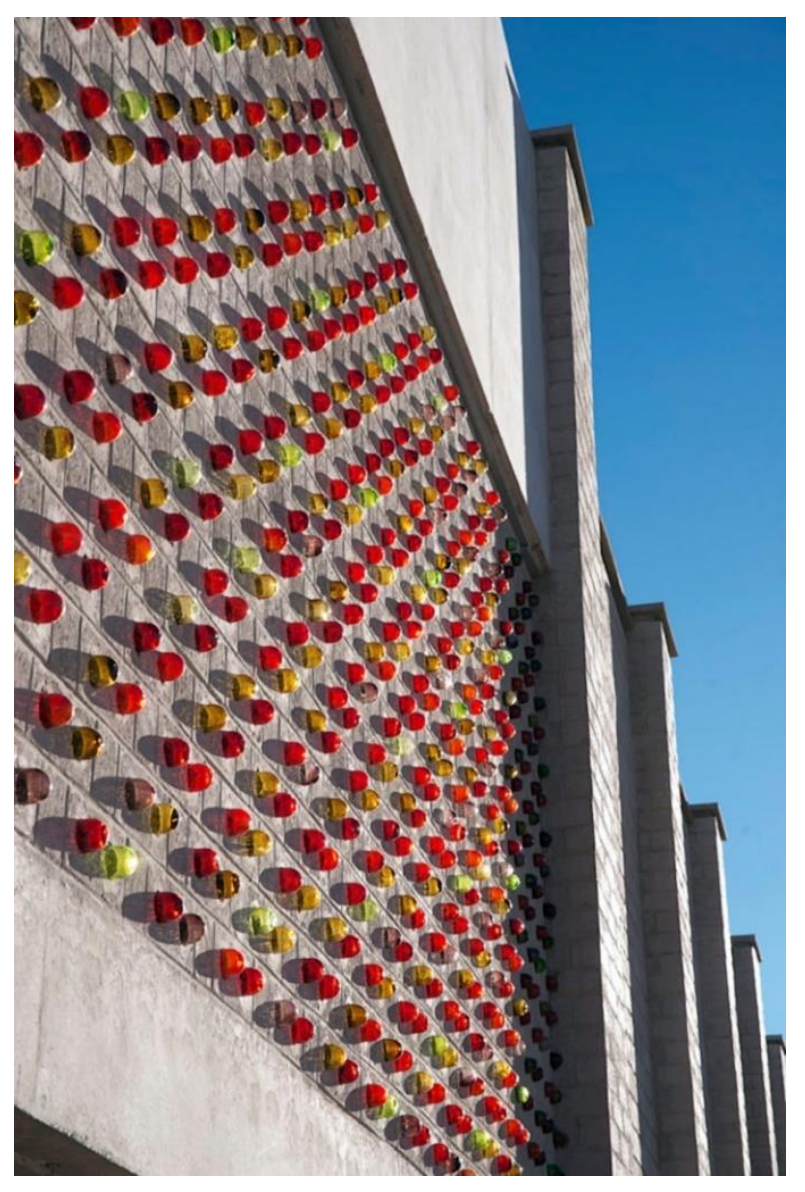

Fig. 12. Inserción de copas de cristal en Viñedos de Coté. Fuente: Fuente: Fotografía de Jaime Navarro.

surgieron a partir del diseño de paisaje considerando la vegetación natural del sitio, están integrados completamente al entorno, a pesar de ser de gran magnitud, apenas se distingue a lo lejos, apunta el arquitecto Alejandro D'Acosta. La mayor parte del proyecto es madera reciclada de la región con estructura de acero. Cubierto por un paisaje elaborado también con la vegetación existente en el sitio, cuenta con un espejo de agua que además de ser parte del diseño funciona como aislante natural. ${ }^{39}$ Para el hotel se fueron creando habitáculos con rocas y jardines para producir un ambiente de privacidad resguardado por árboles y viñedos, logrando que el huésped tenga la impresión de dormir en el jardín. Se fusionan el espacio interior con el exterior utilizando ventanales y puertas corredizas. Se crearon jardines usando la misma tierra del sitio, que forman parte del diseño arquitectónico del lugar. ${ }^{40}$ (Figura 12).

Tierra Adentro, creado en 2016. La arquitecta Fernanda Reyes desarrolló este proyecto que se encuentra en Trancoso, Zacatecas. Es un proyecto joven que nació para continuar un sueño familiar desde 1971, año en que plantaron los primeros viñedos en Campo Real, Zacatecas, y elaboraron vinos de manera rústica. Persiguiendo el sueño del fundador, la segunda y tercera generación de la familia logra abrir sus puertas de la vinícola en 2016. La conformación de la obra está inspirada en el orden lineal y el ritmo de las plantaciones de vid que la rodean; estas hileras representan el trabajo del hombre y su participación en la naturaleza. El proyecto consiste en líneas que se sobreponen y se convierten en volúmenes; cada uno distinguido por su materialidad. La arquitecta Fernanda Reyes describe el proyecto, argumenta que el material protagonista de la obra es la construcción con tierra que es un trabajo artesanal y rústico, como el proceso para crear vino, teniendo también la bondad de ser un proceso sustentable que brinda la arquitectura con las cualidades de la construcción con tierra. ${ }^{41}$

Se utilizan adobes hechos por artesanos mexicanos elaborados en sitio con tierra del mismo terreno. Con la tierra se logra un muro ancho que divide el acceso del área de eventos, y que esconde en su interior servicios sanitarios y cocina. En las fincas antiguas el fundador utilizó adobe, lo que influyó en la elección del material para rescatar la memoria familiar. Un sitio especial para contemplar los viñedos es al límite de la plataforma, en donde se pensó colocar una escultura de forma horizontal para integrarse al paisaje sutilmente, de ahí nace la idea de rescatar

\footnotetext{
${ }^{39}$ Archdaily, 2018.

40 Archdaily, 2014.

41 Archdaily, 2017. Arquine, 2017.
} 
una banca de piedra muy apreciada por el fundador y que se perdió en una restauración de la finca antigua. Una banca escultural que le da la espalda a la construcción para contemplar únicamente el paisaje natural, escuchando un chorro de agua que cae desde el respaldo al canal de agua. ${ }^{42}$

El orgullo de esta obra son las manos de obreros y artesanos mexicanos que hacen posible la realización del proyecto. Los lavamanos están inspirados en los molcajetes mexicanos y hechos especialmente para este proyecto por el artesano galardonado Ignacio García de San Lucas Evangelista, reconocido por su trabajo con la piedra volcánica. El riego y los canales de agua son parte del sistema agrícola. El agua en movimiento es vida y el ser humano por instinto sigue su sonido y su contemplación. Tres elementos con agua en movimiento limitan el terreno elevado para contemplarlos junto al paisaje. De manera perpendicular al pabellón de tierra, se erige un pabellón de acero y cristal, el cual es un mirador con servicio gastronómico desde el que se aprecia la vinícola y los viñedos desde un nivel superior. ${ }^{43}$ (F. Reyes, comunicación personal, 15 de noviembre de 2019) (Figura 13).

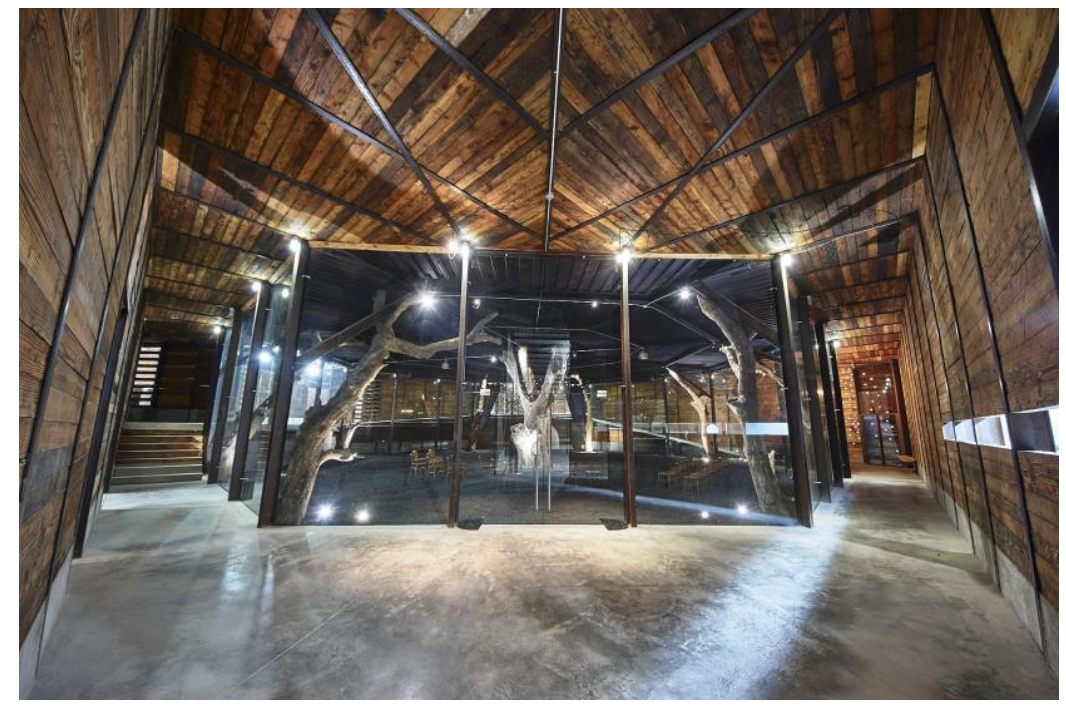

Fig. 13. Madera reciclada y estructura de acero en Vinicola Bruma y hotel boutique Casa 8. Fuente: Fotografía de Javier Zayeck, TAC.

Viñedos y Bodega 1881, creada en 2019. En el despacho Proper Arquitectura desarrollaron el proyecto de esta bodega que se encuentra en San Luis Potosí. El origen de este proyecto son una parte de vestigios históricos de arquitectura vernácula de adobe y lámina encontrados en la zona de los viñedos, en la Hacienda Santa Ana. Se decide recuperarlos y convertirlos en parte de los servicios de la vinícola. Se le da un nuevo uso al adobe y se realizan muros de tapial con tierra de la zona. Si bien no se efectúa un profundo estudio arquitectónico sobre lo más representativo de la arquitectura de la zona, si son un par de vestigios domésticos, casi idénticos, de adobe datados en el siglo XIX. Su configuración, su emplazamiento en el conjunto, su carácter vernáculo y su materialización, son los puntos de partida para desarrollar espacios para hospedaje que ofrezcan servicios al propio viñedo.

El programa está orientado a dar servicio de hospedaje para ejecutivos que disfruten del vino y el contacto con la naturaleza. Aislado de la mancha urbana y rodeado de parras. El concepto

42 Archdaily, 2017.

43 Ibid. 
parte de forma y materia del hallazgo. Se construye una extensión con muros de tierra compactada (tapial), proporcional al rectángulo de adobe existente, con el fin de dar función a los servicios de convivencia social de la suite. Se deja el módulo original para el dormitorio. Articulados por una estructura metálica que vuela desde el módulo nuevo y se aproxima sin tocar al original. Un cuidadoso trabajo con el contexto, el diseño de paisaje y el diálogo entre los muros de tierra proporcionan un ambiente mimético. El proceso de obra lleva un 70 por ciento de avance, se está trabajando con el proyecto del paisaje, donde una acequia que culmina en un pequeño estanque cónico, que se corona con un ahuehuete, rompe con la verticalidad del conjunto. Se espera ofrecer el servicio de hospedaje a inicios del año 2020 (A. Gorab, comunicación personal, 19 de noviembre de 2019) (Figura 14).

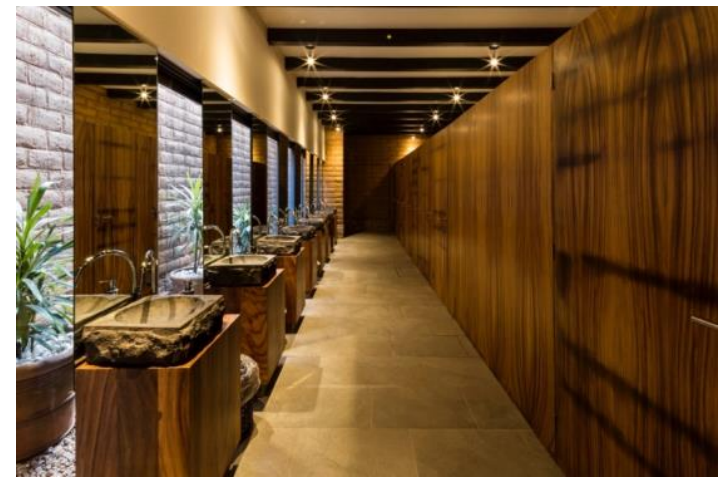

Fig. 14. Lavamanos de piedra volcánica artesanales en Tierra Adentro. Fuente: Fotografía de Onnis Luque, Arq. Fernanda Reyes.

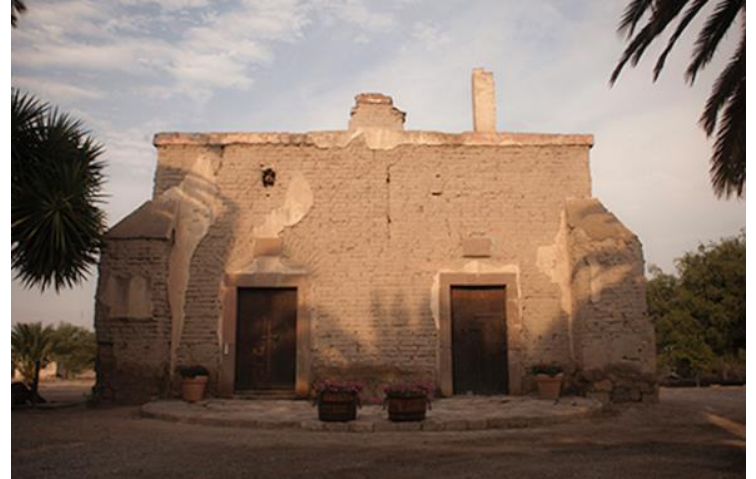

Fig. 15. Edificio de adobe de la Hacienda de Santa Ana en Vinedos y Bodega 1881. Fuente: Fotografía de Antonio Gorab, Properarquitectura.

\section{Conclusión}

Dar una definición concreta y global sobre arquitectura vernácula no es trabajo fácil. Existen diversos puntos de vista influenciados por la gama de tradiciones, culturas y costumbres locales, así como por el tipo de recursos a los que se tiene acceso. Si se retoma la raíz de la palabra "vernáculo" puede uno entender el porqué de la diversidad de interpretaciones. Al derivarse esta palabra de lo nativo, se le relaciona principalmente con las lenguas o dialectos de la gente. Muchas veces consideran la arquitectura vernácula perteneciente a gente con poca cultura, popular y sin sofisticación. Por otro lado, es evidente que este tipo de arquitectura requiere conocimientos del clima, terreno, de los elementos constructivos y las necesidades de la población, así como de los valores y necesidades de la comunidad, lo cual le da características más complejas.

La arquitectura vernácula, al integrarse al ambiente, utiliza materiales orgánicos o reutiliza materiales de fácil acceso, es particularmente sostenible, sin embargo, también busca soluciones arquitectónicas que produzcan un buen aislamiento térmico y el aprovechamiento máximo del agua. Sus premisas principales son la funcionalidad y la sostenibilidad. Por lo tanto, existen varios elementos que conforman la arquitectura vernácula, así como diversos puntos de vista para conceptualizarla. Hoy en día, a pesar de que hay muchos proyectos arquitectónicos que apuestan por la modernidad y la moda, hay también proyectos que apuestan por el rescate de lo vernáculo cuya base es el respeto por la naturaleza, la utilización de los recursos al alcance y sustentabilidad. Se encontraron algunos proyectos vitivinícolas contemporáneos en México que están influenciados por la arquitectura vernácula, cuyos elementos principales son el respeto por la ecología, el entorno del viñedo y la reutilización de elementos a su alcance (Cuadro 1). 
María José Fernández Barberena - Paula Revenga Domínguez

Se está viviendo una época en que la contaminación visual y ambiental es alarmante lo que ha creado una consciencia de la importancia de rescatar los recursos que están disponibles y difundir esa responsabilidad. Una forma de lograrlo es retomando los elementos de la arquitectura vernácula y elaborar proyectos sustentables comprometidos con el medio ambiente. Venturosamente hay cada vez más personas comprometidas con la ecología, con el respeto por la naturaleza, con la reutilización de deshechos y recursos del lugar, con la integración con el paisaje y que valoran el trabajo artesanal. Inclusive los mismos arquitectos tienen como filosofía aprovechar los recursos disponibles, la adecuación del proyecto al medio físico y mantener el equilibrio de los ecosistemas.

En este trabajo se logró encontrar características vernáculas en diversos proyectos de vitivinícolas mexicanas y entender los elementos vernáculos que los arquitectos buscaron imbuir en éstos. Está claro que la arquitectura vernácula ha perdurado en el tiempo y su manera de resolver las necesidades comunitarias ha demostrado ser eficiente además de respetuosa del medio ambiente. Los arquitectos que se basan en este tipo de arquitectura están conscientes de los problemas ecológicos, climatológicos, de escasez de agua y de recursos, así como de la contaminación que enfrenta el planeta, y ante estos retos buscan soluciones creativas que efectivicen los recursos y reduzcan costos e impactos ecológicos. Una limitante en este trabajo fue que no fue posible contactar personalmente a todos los arquitectos que han desarrollado proyectos con influencia vernácula.

Este trabajo puede servir para crear consciencia de la importancia de las construcciones ecológicas ante la escasez de recursos y el cambio climático que estamos viviendo. Y, por otro lado, los empresarios pueden beneficiarse de un proyecto sustentable y autónomo al utilizar energías renovables y, materiales y mano de obra locales, lo cual reducirá los costos de construcción. Está claro que lo vernáculo puede adaptarse a la tecnología y técnicas de construcción innovadoras, pero a la vez eficientes y rentables. A través de la unión de lo tradicional y lo contemporáneo se pueden desarrollar hermosos proyectos sustentables y funcionales.

\begin{tabular}{|c|c|c|c|c|c|c|c|c|c|c|}
\hline Vititinicola & Año & Arquitectos & Lugar & Elementos & & & & & & \\
\hline Casa de Piedra & 1995 & TAC & BC & Lámina usada & Madera barricas & Piedra & & & & \\
\hline Santo Tomás & 1998 & TAC & $\mathrm{BC}$ & Acero & Bodega enterrada & Madera & Neumáticos usados & Postes de luz & Sistema de gravedad & Tierra \\
\hline Dos Búhos & 2003 & Dueño & Guanajuato & Adobe & Adaptación caballerizas & Pacas aplanadas & Vigas de madera & & & \\
\hline Solybarro & 2005 & Dueño Aimé Desponds & BC & Arcilla & Arena & Heno & Piedras & & & \\
\hline Paralelo & 2006 & TAC & $\mathrm{BC}$ & Tapial & Paisaje & Madera & Neumáticos usados & & & \\
\hline Estación de oficios el Porvenir & 2007 & TAC & $\mathrm{BC}$ & Botellas de vidrio & Madera barricas & Tierra & & & & \\
\hline Cuna de tierra & 2011 & $\mathrm{CCA}$ & Guanajuato & Acero & Concreto & Madera & Tepetate & & & \\
\hline Encuentro Guadalupe & 2011 & Gracia Estudio & $\mathrm{BC}$ & Acero & Madera & Material reciclados & & & & \\
\hline Vena Cava & 2012 & TAC & $\mathrm{BC}$ & Deshechos marinos & Tierra & & & & & \\
\hline Clos de Tres Cantos & 2014 & TAC & $\mathrm{BC}$ & Botellas & Hierro de barcos & Madera & Piedra & Páneles solares & Reutilizacion de agua & Vidrio \\
\hline Monte Xanic & 2014 & Juan Garduño & $\mathrm{BC}$ & Arena & Cuerda henequén & Tierra & Piedra & Reutilizacion de agua & Sistema de gravedad & Vegetación endémica \\
\hline Viñedos de Coté & 2014 & Serrano Monjaraz & Querétaro & Tierra & Cristal & Madera & Metal & Sistema de gravedad & & \\
\hline Bruma y Casa 8 & 2015 & TAC & $\mathrm{BC}$ & Acero & Madera & Vegetación endémica & Piedra & & & \\
\hline Tierra Adentro & 2016 & Fernanda reyes & Zacatecas & Adobe & Acero & Vegetación endémica & Piedra volcánica & & & \\
\hline Viñedos y Bodega 1881 & 2019 & Proper Arquitectura & SLP & Adobe & Lámina & Vegetación endémica & & & & \\
\hline
\end{tabular}

Fig. 16. Cuadro 1. Proyectos arquitectónicos y elementos utilizados Fuente: Elaboración propia. 
Influencia de la arquitectura vernácula en las bodegas de vino mexicanas

\section{Bibliografía}

ArchDaily. Hotel Encuentro Guadalupe / graciastudio [en línea] disponible en https://www.archdaily.mx/search/mx/all?q=encuentro\%20guadalupe\&ad_source=jvheader [consulta: 6 octubre 2020]. 2012.

ArchDaily. Vinícola Cuna de Tierra/CCA Centro de Colaboración Arquitectónica [en línea] disponible en https://www.archdaily.mx/mx/02-302113/vinicola-cuna-de-tierra-cca [consulta: 20 octubre 2020]. 2013.

ArchDaily. Reciclaje de Materiales en México: Estación de Oficios El Porvernir [en línea] disponible en https://www.archdaily.mx/mx/02-355288/reciclaje-de-materiales-en-mexico-estacion-deoficios-el-porvenir?ad_source $=$ search\&ad_medium $=$ search_result_all [consulta: 6 octubre 2020]. 2014.

ArchDaily. Vinícola Bruma/Alejandro D'Acosta [en línea] disponible en https://www.archdaily.mx/mx/802145/vinicola-bruma-tac-taller-de-arquitecturacontextual [consulta: 20 de octubre 2020]. 2014.

Archdaily. Jardin y Restaurante Tierra Adentro/Fernanda Reyes [en línea] disponible en https://www.archdaily.mx/mx/885279/jardin-y-restaurante-tierra-adentro-fernanda-reyes. 2017

Arquine. Tierra Adentro. [en línea] disponible en https://www.arquine.com/tierra-adentro/ [consulta: 20 octubre 2020]. 2017.

Arquitecturayempresa (2014). Hotel Encuentro Guadalupe un eco-hotel en México [en línea] disponible en https://arquitecturayempresa.es/noticia/hotel-encuentro-guadalupe-un-eco-hotel-enmexico [consulta: 8 octubre 2020]. 2014.

Arquitectura Panamericana. Vinicola VMX [en línea] disponible en http://www.arquitecturapanamericana.com/vinicola-vmx/ [consulta: 18 de octubre 2020]. 2014.

Arquitectura Panamericana. Viñedo de Coté [en línea] disponible en http://www.arquitecturapanamericana.com/vinedo-de-cote/ [consulta: 17 de octubre 2020].

Benavides Solís, J. "La arquitectura vernácula, una memoria rota". Revista PH: Boletín Andaluz. del Patrimonio Histórico, vol. 5, no 20, (1997), España, 2014, pp. 60-64.

Brown, R. y Maudlin, D. "Concepts of vernacular architecture". The Sage handbook of architecture theory, (2012), 2014, p. 340-368.

Calamia, P. “Architettura rurale e valorizzazione del patrimonio culturale in Sicilia”. UCOARTE. Revista De Teoría E Historia Del Arte, 9, 2020, pp. 92-105.

Cob Building: What is Cob? [En línea] disponible en https://www.thehollies.ie/cob/ [consulta 25 octubre 2019]. 202.

Chaos Yeras, M. T. "La arquitectura vernácula como importante manifestación de la cultura". Arquitectura del sur, vol. 33, n 47, (2015), Chile, pp. 62-73.

D'Acosta, Al. (s.f.). Alejandro D'Acosta Arquitecto [en línea] disponible en https://www.tac.mx [consulta: 10 octubre 2020].

D’Acosta A. Vinícola Santo Tomás. México: ISSUU [en línea] disponible en https://issuu.com/alejandrodacosta/docs/vinicola_santo_tomas_ [consulta: 5 octubre 2020]. 2011.

Diáñez Rubio, P. "Más allá de identificación. Interpretar la arquitectura vernácula". En Arquitectura vernácula en el mundo ibérico: actas del congreso internacional sobre arquitectura vernácula. Sevilla: Universidad Pablo de Olavide, 2007, pp. 53-55. 
García, A./Meraz, L./Díaz, E. R. "Wine tourism and wine marketing in family-owned micro wineries in Guadalupe Valley, Mexico”. En Rosa Dos Ventos, vol. 10, n 4, Brasil, 2018, pp. 690-711.

García, A./Rivera, E. "El valor añadido de la arquitectura vernácula: los casos de la Ruta del Vino y del Tequila en México". En Pasos, vol. 17, no 2, México, 2019, pp. 267-284.

ICOMOS. Carta del Patrimonio Vernáculo Construido (1999). Ratificada por la 12a Asamblea General de México, en octubre de 1999 [en línea] disponible en https://www.icomos.org/charters/vernacular_sp.pdf [consulta: 4 octubre 2020]. 1999.

King, J. L. La arquitectura vernácula del Noreste de México [en línea] disponible en https://repositories.lib.utexas.edu/handle/2152/4091 [consulta: $1^{\circ}$ noviembre 2020]. 2001.

Landa Contreras, V./Segura Contreras, G.: "Algunas reflexiones sobre la arquitectura vernácula”. En Cuadernos de Arquitectura, vol. 7 n 7, México, 2017, pp. 67-71.

Maldonado, D. ¿Arquitectura vernácula urbana? [en línea] disponible en https://vitruvius.com.br/revistas/read/arquitextos/13.154/4664 [consulta: 12 octubre 2020]. 2013.

Oliver, P. Built to meet needs: Cultural issues in vernacular architecture. Londres: El Sevier/Architectural Press. 2006.

Ortiz, E. "Arquitectura vernácula-Arquitectura con arquitectos: una interacción fecunda en riesgo de extinción”. En Ciudad Altrernativa, n 14, Ecuador, 1999, pp. 141-148.

Ortiz, R. "La trascendencia de la arquitectura vernácula". En Stringel Rodriguez M. de los A. et al (eds.) (2015), Responsabilidad social de la arquitectura en el contexto actual. México: Asociación de Instituciones de Enseñanza de la Arquitectura de la República Mexicana, 2015, pp. 104-113.

Puerto, A. del. "Una lectura paralela de historia y arquitectura vernácula agrícola entre los Montes de Toledo y el río Tajo", UCOARTE. Revista De Teoría E Historia Del Arte, 3, 2014, pp. 95116.

Revista Milenio. Estoy fuera del star system de los arquitectos [en línea] disponible en https://www.milenio.com/estilo/estoy-fuera-del-star-system-de-los-arquitectos [consulta: 8 octubre 2020]. 2014.

Revenga Domínguez, P. "Hacia una adecuada utilización del Patrimonio como recurso turístico", Areté Documenta. Boletín de la Asociación Española de Gestores del Patrimonio, n 16, 2002, pp. 113-124.

Revenga Domínguez, P. "Metodologías, interpretaciones y tributos de la historia del arte" en José Luis Palacio Prieto, Ligia Fernández Flores, Jorge Antonio Muñoz Figueroa, Martha Jurado Salinas (coords.), 90 años de cultura. Centro de Enseñanza para Extranjeros, 2012, pp. 87-125.

Teorizando1arquitectura. Nueva Arquitectura en Baja California [en línea] disponible en https://teorizando1arquitectura.wordpress.com/2018/06/12/nueva-arquitectura-en-bajacalifornia/ [consulta: 18 octubre 2020]. 2018.

Tillería, J. "La arquitectura sin arquitectos, algunas reflexiones sobre arquitectura vernácula”. En AUS, no 8, Chile, 2010, pp. 12-15.

Torres Zárate, G. “Arquitectura vernácula y sustentabilidad”. En Revista Horizontes, no 3, México, 2003, pp. 12-21.

Torres Zárate, G. "Deterioro del patrimonio vernáculo". En La Gaceta, vol. 1, no 3, México, 2005, pp. 20-25. 
Torres Zárate, G. Arquitectura vernácula, fundamento de la enseñanza de sustentabilidad [en línea] disponible en https://sistemamid.com/panel/uploads/biblioteca/2014-04-27_01-194998077.pdf [consulta: 18 octubre 2020]. 2009.

Torres Zárate, G. “Arquitectura vernácula y sustentabilidad”. En Horizontes, no 3, 2011, pp.1619.

Urquiza, I. (s. f.). Ignacio Urquiza Arquitectos [en línea] disponible en https://ignaciourquiza.mx/cuna-de-tierra/ [consulta: 20 octubre 2020].

Viñuales, G. M. Arquitectura vernácula en Iberoamérica: historia y persistencias. En Arquitectura vernácula en el mundo ibérico: actas del congreso internacional sobre arquitectura vernácula, 2007, pp. 1524. Universidad Pablo de Olavide, Sevilla.

World-architects. Viñedo de Coté. [en línea] disponible en https://www.worldarchitects.com/zh/serrano-monjaraz-arquitectos-mexico-d-f/project/vinedo-decote [consulta: 18 de octubre 2020]. 2014. 